\title{
The Body Composition in Early Pregnancy is Associated with the Risk of Development of Gestational Diabetes Mellitus Late During the Second Trimester
}

This article was published in the following Dove Press journal:

Diabetes, Metabolic Syndrome and Obesity: Targets and Therapy

\author{
Yanping Liu (iD ${ }^{1, *}$ \\ Jing $\operatorname{Liu}^{2, *}$ \\ Yinjie $\mathrm{Gao}^{3}$ \\ Dan Zheng ${ }^{2}$ \\ Wei $\operatorname{Pan}^{2}$ \\ Min $\mathrm{Nie}^{3}$ \\ Liangkun $\mathrm{Ma} \mathbb{D}^{4}$

\begin{abstract}
'Department of Clinical Nutrition, Peking Union Medical College Hospital, CAMS and PUMC, Beijing 100730, People's Republic of China; ${ }^{2}$ Guiyang Maternal and Child Health Care Hospital, Guiyang Children's Hospital, Beijing 100730, People's Republic of China; ${ }^{3} \mathrm{NHC}$ Key Laboratory of Endocrinology, Department of Endocrinology, Peking Union Medical College Hospital, Peking Union Medical College, Chinese Academy of Medical Sciences, Beijing 100730, People's Republic of China; ${ }^{4}$ Department of Obstetrics \& Gynecology, Peking Union Medical College Hospital, Peking Union Medical College, Chinese Academy of Medical Sciences, Beijing 100730, People's Republic of China
\end{abstract}

*These authors contributed equally to this work.

\begin{abstract}
Objective: Gestational diabetes mellitus (GDM) causes both short- and long-term harm to mothers and fetuses. It is important to predict the occurrence of GDM as early as possible and take adequate measures to prevent it. The purpose of this study was to investigate the association between body composition of pregnant women in early pregnancy and the risk of GDM.
\end{abstract}

Subjects and Methods: A total of 1318 pregnant women in the early stage of pregnancy were recruited from the Guiyang Maternal and Child Health Care Hospital. Detailed clinical data were recorded. Body composition was determined using the bioimpedance method at 13 weeks of gestation. The association between BMI before pregnancy (pre-BMI), fat mass percentage (FMP) and skeletal muscle mass percentage (SMMP) and the results of glucose tolerance screening in the second trimester of pregnancy were analyzed. Fat mass index (FMI) was calculated using fat mass in kilograms as measured using BIA at 13 weeks of pregnancy divided by the square of the woman's height in meters $\left(\mathrm{kg} / \mathrm{m}^{2}\right)$ and was analyzed to determine the predictive effect of body fat on GDM.

Results: Of the 1318 participants, 249 were diagnosed with GDM and 1069 with normal blood glucose. The FMI and FMP in GDM were higher than in NGT $(P<0.001)$, while the SMMP in GDM was lower than in NGT $(P<0.001)$. Overweight women (pre-BMI $\geq 24 \mathrm{~kg} / \mathrm{m}^{2}$ ) had a higher risk of developing GDM than women with normal pre-BMI (adjusted OR 2.604, 95\% CI 1.846-3.673). Women with FMP greater than $28 \%$ had a higher risk of developing to GDM than women with normal-range FMP (adjusted OR 1.572, 95\% CI 1.104-2.240). When FMI is used to predict the incidence of GDM, the area under the curve (AUC) is $65.8 \%$, which is comparable to $\mathrm{BMI}$ ( $\mathrm{AUC}=67.2 \%$ ).

Conclusion: Body composition early during gestation is associated with the risk of GDM. The fat mass index in early pregnancy is a predictor of GDM, and it could be an indicator of the efficacy of any intervention to reduce the risk of GDM.

Keywords: gestational diabetes mellitus, body composition, fat mass percentage, fat mass index, skeletal muscle mass percentage

\section{Introduction}

Gestational diabetes mellitus (GDM) is diabetes that occurs or first diagnosed during pregnancy. The incidence of GDM is about $2.3-29.6 \%$ in different ethnic groups, and it has increased significantly in recent years. ${ }^{1}$ At present, $2 \mathrm{~h}, 75 \mathrm{~g}$ oral glucose tolerance test at $24-28 \mathrm{w}$ is used to diagnose GDM in China. Pregnant women with any one of three blood glucose values that are before or 1 or $2 \mathrm{~h}$ after
Correspondence: Min Nie; Liangkun Ma Email nm_pumch@aliyun.com; MaLiangKun@pumch.cn 
taking sugar reaching or exceeding $5.1 \mathrm{mmol} / \mathrm{L}, 10.0$ $\mathrm{mmol} / \mathrm{L}$, and $8.5 \mathrm{mmol} / \mathrm{L}$, respectively, are diagnosed GDM.

GDM is associated with a range of short- and longterm adverse outcomes for the mother and the fetus. ${ }^{2,3}$ The cumulative incidence of type 2 diabetes mellitus (T2DM) in GDM pregnant women within the ten years of delivery can be as high as $60 \% .{ }^{4,5}$ Pregnant women with GDM have a significantly higher risk of giving birth to high or low birth weight babies, ${ }^{6,7}$ who are another potential cause of diabetes. ${ }^{8,9}$ Normal-weight infants born to GDM mothers had a higher incidence of obesity and impaired glucose tolerance during puberty than normal-weight infants born to mothers with normal blood glucose. ${ }^{10}$ This shows that GDM can be an important cause of the increased prevalence of type 2 diabetes, and early detection and intervention of GDM pregnant women are crucial ways to reduce the incidence of type 2 diabetes.

The increased risk of GDM is associated with a variety of factors, including maternal age $\geq 35$ years, excess weight or obesity before pregnancy, polycystic ovary syndrome, family history of diabetes - especially in firstdegree relatives, GDM, and macrosomia delivery history. Excessive body fat is a significant risk factor for GDM. ${ }^{11}$ A few studies investigated the association between adiposity and gestational diabetes mellitus. Visceral and abdominal subcutaneous fat thickness measured by ultrasound during the first trimester of pregnancy may be associated with the risk of developing GDM during the second trimester of pregnancy. ${ }^{12-16}$ Nassr showed that body fat index, which is calculated by multiplying the thickness of pre-peritoneal by that of subcutaneous fat and then dividing by the patient's height, is an excellent predictor of the development of GDM. ${ }^{17}$

Conventional methods for assessing body composition in pregnancy include anthropometry, density measurement, and hydrometry. Bioelectrical impedance analysis (BIA) is a hydrometric method, and it allows accurate estimates of body composition early in pregnancy (14 weeks), as confirmed by comparison to deuterium dilution. ${ }^{18}$ BIA is widely used for measuring body composition in China due to its inexpensiveness and practicability.

Abnormal body composition (high body fat and low skeletal muscle mass percentage) caused by excessive diet and a sedentary lifestyle can be corrected. If the value of abnormal body composition in GDM prediction can be clearly established, it can be used to begin early intervention to prevent the occurrence of GDM rather than intervene after it occurs. We here aimed to investigate the relationship between body composition measured by BIA at 13 weeks of pregnancy and GDM diagnosed during the late second trimester.

\section{Subjects and Methods Study Design}

This study retrospectively recruited pregnant women who delivered in Guiyang Maternal and Child Health Care Hospital (Guizhou Province, China). Written informed consent was obtained from all participants. The study was approved by the ethics committee of Peking Union Medical College Hospital (Protocol ID: S-K443) and in accordance with the Declaration of Helsinki.

\section{Participants}

A total of 5127 healthy pregnant women with low-risk pregnancies delivered in Guiyang Maternal and Child Health Care Hospital from January 2018 to May 2018. Since many pregnant women do not attend antenatal care at the same hospital throughout their pregnancy, which results in incomplete information, and only some of them agreed to undergo body composition testing, a total of 1,745 pregnant women had complete prenatal follow-up records in this hospital. Excluding 34 pregnant women with non-singleton and 393 pregnant women for whom oral glucose tolerance test (OGTT) records were not available, a total of 1318 pregnant women were included in the study (Figure 1). The obstetric records of parturient and the hospital records of newborn were extracted from the prenatal care manual and discharge summary. All participants underwent a diagnostic $2 \mathrm{~h} 75 \mathrm{~g}$ OGTT between 24 and 28 weeks. Women with at least one elevated glucose value based upon the IADPSG criteria (fasting $\geq 5.1 \mathrm{mmol} / \mathrm{L}$ (92 mg/dl), $1 \mathrm{~h} \geq 10.0 \mathrm{mmol} / \mathrm{L}(180 \mathrm{mg} / \mathrm{dl})$, or $2 \mathrm{~h} \geq 8.5 \mathrm{mmol} / \mathrm{L}$ $(153 \mathrm{mg} / \mathrm{dl}))$ were diagnosed with GDM. All other results were considered normal glucose test results (NGT). The exclusion criteria were as follows: (i) non-singleton pregnancy, (ii) pregnancies complicated by pre-gestational or gestational systemic diseases, such as hypertension, thyroid disorder, genetic history, infection or hepatitis, (iii) overt diabetes, (iv) evidence of congenital fetal malformations detected by ultrasonography, and (v) polyhydramnios.

\section{Sample Size and Power Calculation}

The sample size of the cohort was designed to detect a minimal odds ratio (OR) of 1.85 for GDM in overweight 


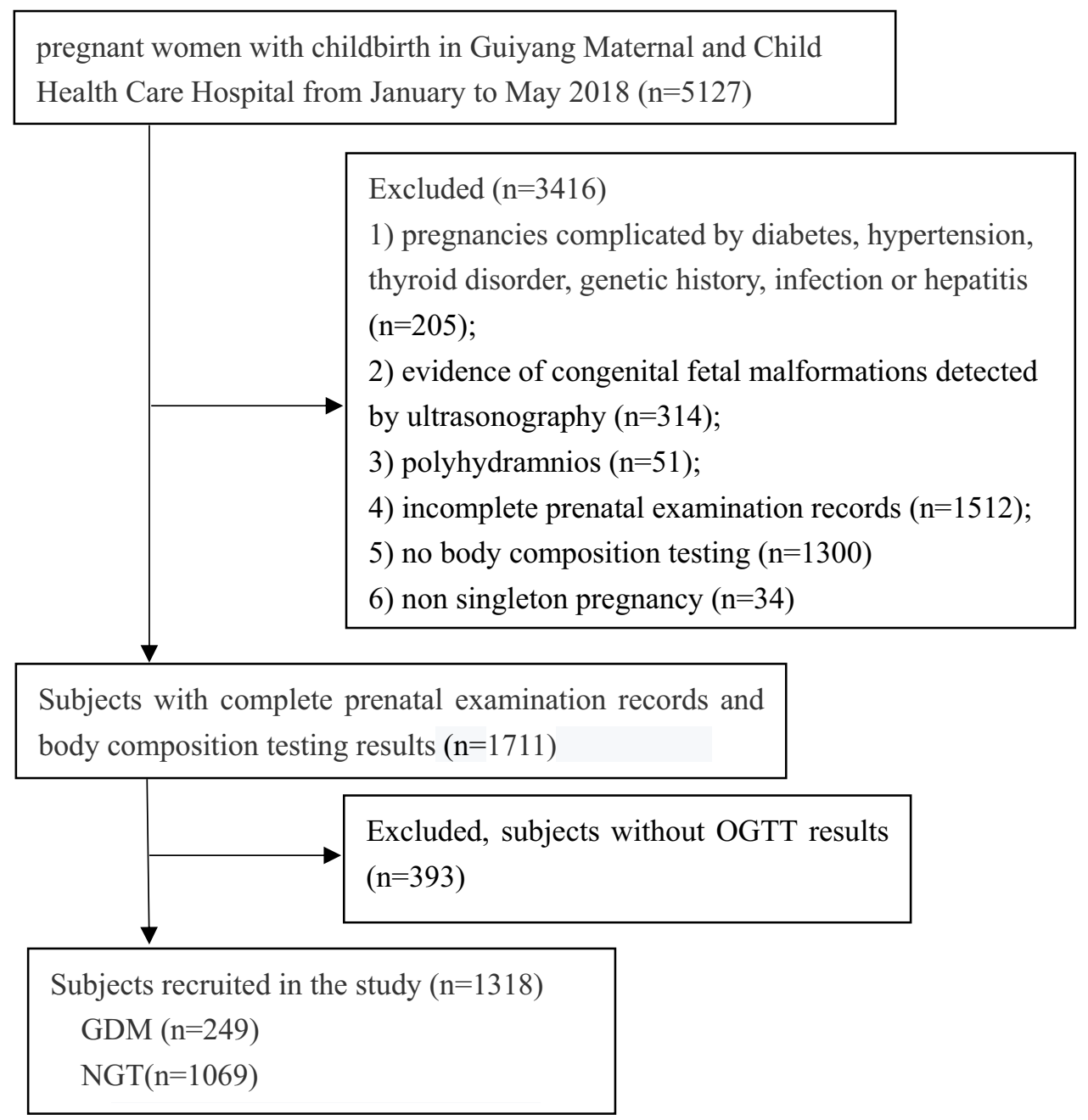

Figure I Flowchart showing enrollment in the study.

pregnant women during the first term of pregnancy, which was referred to previous study that reported OR values ranging from 1.85 to 5.70 in overweight pregnant women. ${ }^{19-21}$ The sample allocation ratio between two groups was set at 5 with the incidence of GDM being about $20 \%$ in China. ${ }^{22-24}$ The calculation also took into account other parameters, including an expected prevalence of GDM in normalweight women of $10.0 \%$, a power of $80.0 \%$, and a twotailed $\alpha$ of 0.05 . Based on these prerequisites, the theoretical sample size is 1242, consisting of GDM group 207 and control group 1035. We finally included 1318 pregnant women, including 249 diagnosed as GDM and 1069 normal. For power analysis, given the above common parameters, we validated our sample size was able to achieve $85.27 \%$ power to detect an odds ratio in the group proportions of 1.85. All calculations were performed by PASS 15 software (NCSS, LLC. Kaysville, Utah, USA. www.ncss.com).

\section{Measurements}

Maternal age, height, pre-pregnancy body weight, and neonatal body weight were recorded. Body composition was measured in fasting and after urination by using the Body Composition Analyzer (Inbody720, Korea) according to the manufacturer's instructions in 13 weeks of pregnancy. Maternal age was classified as " $\geq 25$ years" and " $<25$ years". Body mass index before pregnancy (Pre-BMI) was calculated using weight in kilograms during the three months before pregnancy, which was self-reported by the participants, divided by the square of the patient's height in meters $\left(\mathrm{kg} / \mathrm{m}^{2}\right)$. Pre-BMI was categorized into 3 groups according to the standard of BMI for Chinese adults proposed by the Working Group on Obesity in China (WGOC): underweight $\left(<18.5 \mathrm{~kg} / \mathrm{m}^{2}\right)$, normal $\left(18.5-23.99 \mathrm{~kg} / \mathrm{m}^{2}\right)$, overweight $\left(\geq 24 \mathrm{~kg} / \mathrm{m}^{2}\right.$ ). Fat mass index (FMI) was calculated using fat mass in kilograms measured by BIA in 13 weeks of 
pregnancy divided by the square of the woman's height in meters $\left(\mathrm{kg} / \mathrm{m}^{2}\right)$. Fat mass percentage (FMP) and skeletal muscle mass percentage (SMMP) were calculated using fat mass and skeletal muscle mass in kilograms as measured using BIA in 13 weeks of pregnancy divided by the body weight, respectively. FMP was categorized into 3 groups: insufficient $(<18 \%)$, normal $(18-28 \%)$, and excess $(>28 \%)$. Macrosomia was defined as birthweight of more than 4000 $\mathrm{g}$ and low birth weight as lower than $2500 \mathrm{~g}$.

\section{Statistical Analysis}

Results are expressed as the mean \pm standard deviation (SD). The relationships between GDM and clinical data, including age, FMI, FMP, SMMP, pre-BMI, were evaluated using Spearman's rank correlation analysis. The chisquare $\left(\chi_{\chi}^{2}\right)$ test was used to conduct statistical comparisons of categorical data. The independent sample $t$-test was carried out to assess the differences among continuous data. Logistic regression analysis was performed to assess the potential predictors for the development of GDM. Factors found to be statistically significant according to univariate logistic regression were considered confounding variables in the multivariable logistic regression model. The crude and adjusted odds ratios (OR) and $95 \%$ confidence intervals $(\mathrm{CI})$ were calculated by univariate and multivariate logistic regression, respectively. The receiver-operating characteristic (ROC) curves were constructed to calculate the area under the curve (AUC) for different measures of pre-BMI and FMI in predicting GDM, and Delong's test was used to compare the areas under two ROC curves (Med Calc) named above. All analyses were performed using the IBM SPSS Statistics 21.0 (Armonk, NY, USA), and statistical significance was set at $P<0.05$.

\section{Results}

Of the 1318 pregnant women, 249 were GDM, and 1069 were NGT. The prevalence of GDM was $18.9 \%$. The demographic and clinical characteristics of the patients are presented in Table 1. The participants in the GDM group tended to be older than those in the NGT group $(32.6 \pm 5.1$ vs 30.1 \pm 4.8 ). The FMI, FMP, and glucose of 3-point OGTT in GDM were higher than in NGT $(P<0.001)$, while the SMMP in GDM was lower than in NGT $(P<0.001)$.

There was a positive correlation between GDM and age, pre-BMI, FMP, and a negative correlation between GDM and SMMP (Table 2).
Table I Comparison of Clinical Characteristics Between Pregnant Women with Normal Glucose Test and Gestational Diabetes Mellitus

\begin{tabular}{|c|c|c|c|}
\hline & $\begin{array}{l}\text { NGT } \\
(n=1069)\end{array}$ & $\begin{array}{l}\text { GDM } \\
(n=249)\end{array}$ & $p$ value \\
\hline Age (yrs) & $30.1 \pm 4.8$ & $32.6 \pm 5.1$ & $<0.001$ \\
\hline Pre-BMl $\left(\mathrm{kg} / \mathrm{m}^{2}\right)$ & $21.40 \pm 2.76$ & $23.25 \pm 3.50$ & $<0.001$ \\
\hline Weeks ${ }^{\mathrm{a}}$ (wks) & $11.8 \pm 2.0$ & $11.9 \pm 2.1$ & 0.654 \\
\hline Fat mass index $\left(\mathrm{kg} / \mathrm{m}^{2}\right)$ & $6.00 \pm 1.91$ & $7.14 \pm 2.26$ & $<0.001$ \\
\hline Fat mass percentage (\%) & $27.5 \pm 5.6$ & $30.1 \pm 5.8$ & $<0.001$ \\
\hline $\begin{array}{l}\text { Skeletal muscle mass } \\
\text { percentage (\%) }\end{array}$ & $43.0 \pm 10.8$ & $40.0 \pm 8.3$ & $<0.001$ \\
\hline Glucose (0) ${ }^{b}$ & $4.5 I \pm 0.29$ & $5.22 \pm 0.62$ & $<0.001$ \\
\hline Glucose $(\mathrm{Ihr})^{\mathrm{b}}$ & $7.06 \pm 1.36$ & $9.74 \pm 1.79$ & $<0.001$ \\
\hline Glucose $(2 \mathrm{hr})^{b}$ & $6.30 \pm 0.97$ & $8.17 \pm 1.51$ & $<0.001$ \\
\hline Body weight of neonate & $3.27 \pm 0.47$ & $3.30 \pm 0.42$ & 0.244 \\
\hline Macrosomia, n (\%) & $4 I(3.8)$ & $9(3.6)$ & 0.871 \\
\hline
\end{tabular}

Notes: ${ }^{a}$ The gestation week to measure the body composition. ${ }^{\mathrm{b}}$ The plasma glucose level of $75 \mathrm{~g}$ OGTT.

Abbreviations: NGT, normal glucose test; GDM, gestational diabetes mellitus.

Mothers over 25 years of age were more likely to have increased risk of GDM than those who were younger (20.0\% vs $7.3 \%, P<0.001)$ (Table 3 ), even after adjusting for pre-BMI and FMP (adjusted $\mathrm{OR}=2.326$, 95\% CI 1.103-4.903) (Table 4).

Overweight women (pre-BMI $\geq 24 \mathrm{~kg} / \mathrm{m}^{2}$ ) had a higher risk of developing GDM than women with normal preBMI (36.4\% vs 14.7\%, adjusted OR 2.604 (95\% CI 1.846-3.673), controlling for age and FMP) (Tables 3 and 4). Pregnant women with FMP over $28 \%$ had a higher risk of developing GDM than women with normal FMP (OR

Table 2 Correlations Between GDM and Age, Pre-BMI and Body Composition

\begin{tabular}{|l|l|l|}
\hline Variables & $\begin{array}{l}\text { Correlation } \\
\text { Coefficient }\end{array}$ & $p$ value \\
\hline Age & 0.165 & $<0.001$ \\
\hline Pre-BMI & 0.195 & $<0.001$ \\
\hline Fat mass percentage (\%) & 0.157 & $<0.001$ \\
\hline $\begin{array}{l}\text { Skeletal muscle mass } \\
\text { percentage (\%) }\end{array}$ & -0.114 & $<0.001$ \\
\hline
\end{tabular}

Abbreviations: GDM, gestational diabetes mellitus; Pre-BMI, pre-pregnancy BMI. 
Table 3 Number and Percentage of Subjects in Different Age, Pre-BMI and Fat Mass Percentage Group

\begin{tabular}{|c|c|c|c|c|c|}
\hline \multirow[t]{2}{*}{ Characteristics } & \multicolumn{2}{|c|}{ NGT $(n=1069)$} & \multicolumn{2}{|c|}{ GDM $(n=249)$} & \multirow[t]{2}{*}{$p$ value } \\
\hline & Number & Percentage (\%) & Number & Percentage (\%) & \\
\hline \multicolumn{6}{|l|}{ Age (yrs) } \\
\hline$<25$ & 102 & 92.7 & 8 & 7.3 & - \\
\hline$\geq 25$ & 967 & 80.0 & 241 & 20.0 & $<0.05^{\mathrm{a}}$ \\
\hline \multicolumn{6}{|l|}{ Pre-BMI $\left(\mathrm{kg} / \mathrm{m}^{2}\right)$} \\
\hline$<18.5$ & 132 & 87.4 & 19 & 12.6 & $0.494^{\mathrm{b}}$ \\
\hline$\geq 18.5$ and $<24$ & 766 & 85.3 & 132 & 14.7 & - \\
\hline$\geq 24$ & $|7|$ & 63.6 & 98 & 36.4 & $<0.00 \mathrm{I}^{\mathrm{b}}$ \\
\hline \multicolumn{6}{|l|}{ Fat mass percentage (\%) } \\
\hline$<18 \%$ & 42 & 85.7 & 7 & 14.3 & $0.68 I^{c}$ \\
\hline$\geq 18 \%$ and $<28 \%$ & 536 & 87.7 & 75 & 12.3 & - \\
\hline$\geq 28 \%$ & 491 & 74.6 & 167 & 25.4 & $<0.001^{\mathrm{c}}$ \\
\hline
\end{tabular}

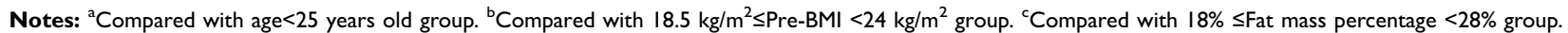
Abbreviations: NGT, normal glucose test; Pre-BMI, pre-pregnancy BMI.

Table 4 Crude and Adjusted Odds Ratios (OR) of the Risk Factors for Gestational Diabetes Mellitus

\begin{tabular}{|c|c|c|c|c|}
\hline Variables & Unadjusted OR (95\% Cl) & p-value & Adjusted OR (95\% Cl) & $\begin{array}{l}\text { Adjusted } \\
\text { p-value }\end{array}$ \\
\hline \multicolumn{5}{|l|}{ Age (yrs) } \\
\hline$<25$ & I & & I & \\
\hline$\geq 25$ & $3.178(1.526-6.616)$ & 0.002 & $2.326(1.103-4.903)^{\mathrm{a}}$ & 0.027 \\
\hline \multicolumn{5}{|c|}{ Prepregnancy BMI } \\
\hline Normal & 1 & & 1 & \\
\hline$<18.5$ & $0.835(0.499-1.398)$ & 0.494 & $1.040(0.582-1.858)$ & 0.895 \\
\hline$\geq 24.0$ & $3.326(2.440-4.532)$ & $<0.001$ & $2.604(1.846-3.673)^{\mathrm{b}}$ & $<0.001$ \\
\hline \multicolumn{5}{|c|}{ Fat mass percentage } \\
\hline Normal & 1 & & 1 & \\
\hline$<18 \%$ & $1.191(0.516-2.748)$ & 0.682 & $1.242(0.510-3.024)$ & 0.634 \\
\hline$\geq 28 \%$ & $2.43 I(I .803-3.277)$ & $<0.001$ & $1.572(1.104-2.240)^{c}$ & 0.012 \\
\hline
\end{tabular}

Notes: ${ }^{a}$ Mothers over 25 years of age were more likely to have increased risk of GDM than those who were younger after adjusting for pre-BMI and FMP. ${ }^{\mathrm{b}} \mathrm{Overweight}$ women (pre-BMI $\geq 24 \mathrm{~kg} / \mathrm{m}^{2}$ ) had a higher risk of developing GDM than women with normal pre-BMI after adjusting for age and FMP. 'Pregnant women with FMP over $28 \%$ had a higher risk of developing GDM than women with normal FMP after adjusting for age and pre-BMI.

2.431, 95\% CI 1.803-3.277). The risks were slightly lower after controlling for age and pre-BMI (adjusted OR 1.572, 95\% CI 1.104-2.240) (Table 4).

FMI showed a positive relationship to pre-BMI with a correlation coefficient of 0.925 (Figure 2A). ROC curve analysis showed that the AUC was $65.8 \%$ when GDM was predicted by FMI, which is comparable to BMI (67.2\%), and the difference in AUC between FMI and Pre-BMI was not significant $(P=0.093)$ as indicated by DeLong's method (Figure 2B).

Of the 1318 neonates, 50 had macrosomia, 31 were low birth weight, and the others were normal birth weight.
The incidence of macrosomia was 3.8\% (50/1318) in this study. There is no difference in the incidence of macrosomia between NGT or GDM group (Table 1).

\section{Discussions}

We performed a cross-sectional investigation on the association between body composition measured at 13 weeks of gestation and GDM confirmed at 24-28 weeks of gestation and found two main results. First, the prevalence of GDM was $18.9 \%$ using the International Association of Diabetes and Pregnancy Study Groups (IADPSG) criteria, and the risk of GDM increased with age, pre-BMI, and FMP but 

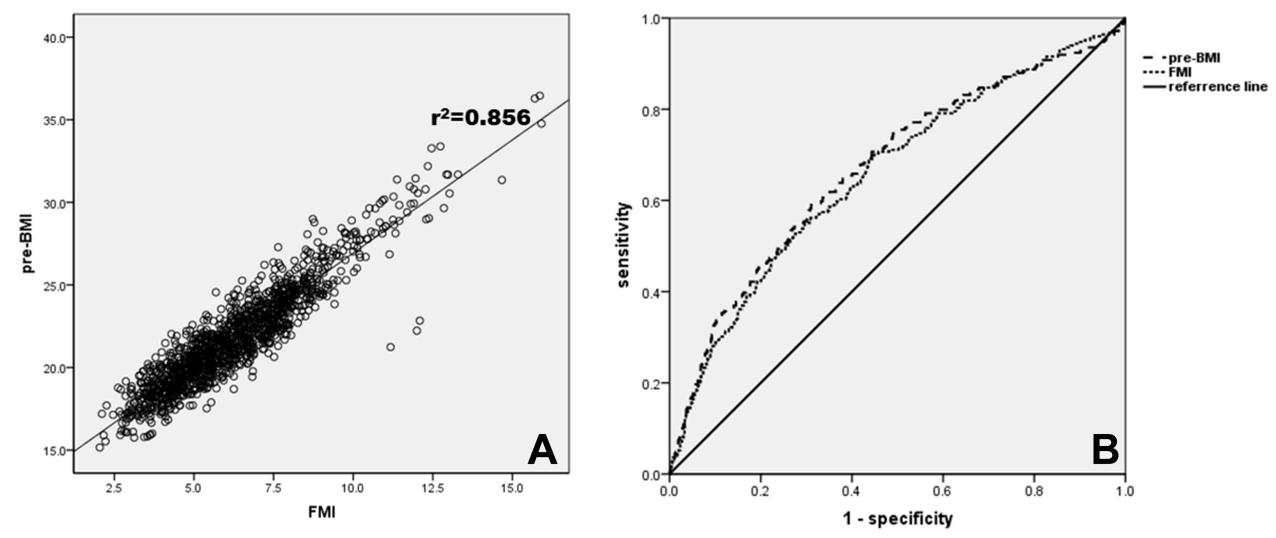

Figure 2 Correlation between pre-BMI and FMI and receiver-operating characteristic (ROC) curve to predict GDM. (A) Correlation between Pre-BMI and FMI. There was a significant correlation between pre-BMl and FMI $(r=0.925, p<0.00 \mathrm{I})$. (B) ROC curve predicts the presence of GDM. The AUC of FMl and Pre-BMI is 0.658 ( $p<0.00 \mathrm{I})$ and $0.672(p<0.001)$, respectively. The DeLong test shows that the difference of AUC between FMI and Pre-BMI is not significant $(p=0.093)$.

decreased slightly with SMMP. Second, when GDM was predicted by FMI, the AUC was $65.8 \%$, which was comparable to that of BMI (AUC $=67.2 \%$ ).

Chinese pregnant women are at high risk of developing GDM. The prevalence of GDM is related to the criteria used. Before 2010, there was no unified method to diagnose GDM in China. After 2010, the IADPSG method was generally recommended to diagnose GDM. Studies in different regions show that the incidence of GDM among Chinese women is between $14.8 \%$ and $19.9 \% .^{22-24}$ Our study also demonstrated that the prevalence of GDM in Guiyang in Guizhou Province was as high as $18.9 \%$, which is comparable to that of other local and regional studies mentioned above.

Maternal age is a definite risk factor for GDM, but there is no consensus about the age above which the prevalence of GDM increases. Some studies have shown that the rate of GDM in women aged over 35 years old was higher than among those under $35,{ }^{23}$ while others showed 25 years to be the lowest cutoff age for the screening for GDM. The recommendations of the American Diabetes Association, ${ }^{19}$ several previous studies, and this study indicated that an age of 25 years or older was associated with an increased prevalence of GDM. A study reported by Lao et al found that screening for GDM among patients 25 and older had a higher predictive value in recognizing GDM. ${ }^{20}$ A meta-analysis by Lee et al showed the OR of GDM among women 25 older to be $2.17 .^{21}$ Our study found that women aged 25 years old and older had 2.499 times the chance of having gestational diabetes in comparison to those under 25 years.

Obesity in the period immediately before pregnancy is one of the main factors underlying the development of GDM. $\mathrm{BMI}$ is commonly used as a marker to assess the severity of obesity. In this study, the BMI cutoffs recommended by WGOC were used. ${ }^{25}$ We found the odds ratio for GDM to be 2.604 (95\% CI 1.846-3.673) in overweight women (preBMI $\geq 24 \mathrm{~kg} / \mathrm{m}^{2}$ ). Our results are consistent with those of previous studies in which the odds of pre-BMI $\geq 24 \mathrm{~kg} / \mathrm{m}^{2}$ for GDM ranged from 1.85 to 5.7 in China. ${ }^{26-28}$

However, previous studies have shown that the Chinese population, like other Asian populations, has a lower BMI but a higher percentage of body fat than Caucasians of similar age and gender. ${ }^{29}$ BMI does not differentiate between bone, muscle, and fat mass, so a simple and inexpensive method of assessing fat mass may be better for predicting the development of GDM. Methods such as bioelectrical impedance analysis for the assessment of fat mass and fat-free mass in pregnant women in the body composition studies have been described. ${ }^{30-35}$ Our study establishes that BIA is a feasible and reproducible method that can be used during pregnancy. We found pregnant women with FMP over 28\% had a higher risk of developing GDM than women with normal FMP (adjusted OR $1.572,95 \%$ CI $1.104-2.240$ ). These results are similar to those of previous studies, in which the visceral fat mass, ${ }^{12}$ thickness of subcutaneous adipose tissue, ${ }^{15}$ and body fat index (thickness of pre-peritoneal fat $(\mathrm{mm}) \times$ thickness of subcutaneous fat $(\mathrm{mm}) /$ height $(\mathrm{cm}))$ were good markers for determining the risk of the development of GDM. ${ }^{17}$ We also found that SMMP was negatively correlated with increased risk of gestational diabetes. According to a study conducted by Kawanabe et al, inadequate appendicular skeletal muscle mass/fat mass ratio is a risk for the development of insulin resistance in Japanese patients with GDM. ${ }^{29}$ Unfortunately, we did not evaluate the relationship between SMMP and insulin resistance since insulin test is not included in the routine 
prenatal examination and we cannot extract the insulin results of the participants from antenatal records.

Our studies further established that the FMI has a positive correlation with pre-BMI $(\mathrm{r}=0.925)$ and is an excellent alternative to pre-BMI ( $\mathrm{AUC}=67.2 \%$ ) for prediction of GDM (AUC $=65.8 \%$ ). Although FMI did not show a stronger predictor of GDM than pre-BMI, it may be suitable for assessing the effectiveness of intervention measures for pregnant women. Wanget al found FMP was a better risk predictor of GDM than pre-BMI, ${ }^{30}$ which seems different from this study. The difference of the two studies is that Wang et al analyzed the prediction of FMP for GDM in the second trimester (G13-20w), while this study investigated the prediction of FMP for GDM in early pregnancy $(<\mathrm{G} 13 \mathrm{w})$. According to the results of Wang's study and this study, it suggests that FMP be a risk predictor of GDM from early term of pregnancy, and as the gestational age increases, FMP becomes a stronger predictor of GDM than pre-BMI.

The incidence of macrosomia is between $3.1 \%$ and $7.8 \%$ in different parts of China. ${ }^{36-39}$ Several studies have shown that excessive gestational weight gain (GWG) is associated with macrosomia, but prepregnancy BMI is not. ${ }^{36}$ Maternal lipid parameters were also found to be independent risk determinants of fetal overgrowth in pregnancies. ${ }^{40}$ Our results showed that the prevalence of macrosomia in Guiyang is $3.8 \%$, which falls near the lower limit for incidence of macrosomia in China.

Several limitations of this study need to be mentioned. First, this is a retrospective study performed at a single center, and the findings need to be verified by other prospective cohort studies. Second, we focused only on the effect of maternal body composition during the first trimester of gestation on the development of GDM, and we did not evaluate any other clinical data such as the family history of diabetes, insulin level, lipid profile, or adipokine levels.

\section{Conclusions}

The incidence of GDM in Guiyang was $18.9 \%$ as determined using the International Association of Diabetes and Pregnancy Study Groups (IADPSG) criteria. Age over 25 years and overweight or obese status immediately prior to pregnancy were all associated with a greater risk of GDM. The body composition in early gestation is associated with the risk of GDM. FMP over 28\% was associated with the increased risk for developing to GDM and higher SMMP with a lower risk of gestational diabetes. The fat mass index in early pregnancy is a predictor of GDM, and it could be an indicator of intervention efficacy to reduce the risk of GDM.

\section{Acknowledgments}

This work was supported by the National Natural Science Foundation of China (Grant No. 81270879). We would like to thank all participants for their participation in the research.

\section{Disclosure}

The authors declare that they have no conflicts of interest.

\section{References}

1. Yuen L, Wong VW, Simmons D. Ethnic disparities in gestational diabetes. Curr Diab Rep. 2018;18(9):68. doi:10.1007/s11892-0181040-2

2. Johns EC, Denison FC, Norman JE, Reynolds RM. Gestational diabetes mellitus: mechanisms, treatment, and complications. Trends Endocrinol Metab. 2018;29(11):743-754. doi:10.1016/j.tem.2018.09.004

3. Metzger BE, Coustan DR, Trimble ER. Hyperglycemia and adverse pregnancy outcomes. Clin Chem. 2019;65(7):937-938. doi:10.1373/ clinchem.2019.303990

4. Tam WH, Yang XL, Chan JCN, et al. Progression to impaired glucose regulation, diabetes and metabolic syndrome in Chinese women with a past history of gestational diabetes. Diabetes Metab Res Rev. 2007;23(6):485-489. doi:10.1002/dmrr.741

5. Ben-Haroush A, Yogev Y, Hod M. Epidemiology of gestational diabetes mellitus and its association with type 2 diabetes. Diabet Med. 2004;21(2):103-113. doi:10.1046/j.1464-5491.2003.00985.x

6. Claesson R, Aberg A, Marsál K. Abnormal fetal growth is associated with gestational diabetes mellitus later in life: population-based register study. Acta Obstet Gynecol Scand. 2007;86(6):652-656. doi:10.1080/00016340701207682

7. Yang J, Cummings EA, O'connell C, Jangaard K. Fetal and neonatal outcomes of diabetic pregnancies. Obstet Gynecol. 2006;108(3 Pt 1):644-650. doi:10.1097/01.AOG.0000231688.08263.47

8. Hong YH, Chung S. Small for gestational age and obesity related comorbidities. Ann Pediatr Endocrinol Metab. 2018;23(1):4-8. doi:10.6065/apem.2018.23.1.4

9. Mahizir D, Briffa JF, Hryciw DH, Wadley GD, Moritz KM, Wlodek ME. Maternal obesity in females born small: pregnancy complications and offspring disease risk. Mol Nutr Food Res. 2016;60(1):8-17. doi:10.1002/mnfr.201500289

10. Boney CM, Verma A, Tucker R, Vohr BR. Metabolic syndrome in childhood: association with birth weight, maternal obesity, and gestational diabetes mellitus. Pediatrics. 2005;115(3):e290-296. doi:10.1542/peds.2004-1808

11. Chu SY, Callaghan WM, Kim SY, et al. Maternal obesity and risk of gestational diabetes mellitus. Diabetes Care. 2007;30(8):2070-2076. doi:10.2337/dc06-2559a

12. Balani J, Hyer SL, Shehata H, Mohareb F. Visceral fat mass as a novel risk factor for predicting gestational diabetes in obese pregnant women. Obstet Med. 2018;11(3):121-125. doi:10.1177/ $1753495 \times 17754149$

13. De Souza LR, Berger H, Retnakaran R, et al. First-trimester maternal abdominal adiposity predicts dysglycemia and gestational diabetes mellitus in midpregnancy. Diabetes Care. 2016;39(1):61-64. doi: $10.2337 / \mathrm{dc} 15-2027$

14. Gur EB, Ince O, Turan GA, et al. Ultrasonographic visceral fat thickness in the first trimester can predict metabolic syndrome and gestational diabetes mellitus. Endocrine. 2014;47(2):478-484. doi:10.1007/s12020-013-0154-1

15. Kansu-Celik H, Karakaya BK, Tasci Y, et al. Relationship maternal subcutaneous adipose tissue thickness and development of gestational diabetes mellitus. Interv Med Appl Sci. 2018;10(1):13-18. doi:10.1556/1646.10.2018.01 
16. Yang SH, Kim C, An HS, An H, Lee JS. Prediction of gestational diabetes mellitus in pregnant Korean women based on abdominal subcutaneous fat thickness as measured by ultrasonography. Diabetes Metab J. 2017;41(6):486-491. doi:10.4093/dmj.2017.41.6.486

17. Nassr AA, Shazly SA, Trinidad MC, El-Nashar SA, Marroquin AM, Brost BC. Body fat index: a novel alternative to body mass index for prediction of gestational diabetes and hypertensive disorders in pregnancy. Eur J Obstet Gynecol Reprod Biol. 2018;228:243-248. doi:10.1016/j.ejogrb.2018.07.001

18. Lof M, Forsum E. Evaluation of bioimpedance spectroscopy for measurements of body water distribution in healthy women before, during, and after pregnancy. J Appl Physiol. 2004;96(3):967-973. doi:10.1152/japplphysiol.00900.2003

19. American Diabetes Association. Gestational diabetes mellitus. Diabetes Care. 2004;27(Suppl 1):S88-90. doi:10.2337/diacare.27.2007.s88

20. Lao TT, Ho L-F, Chan BCP, Leung W-C. Maternal age and prevalence of gestational diabetes mellitus. Diabetes Care. 2006;29 (4):948-949. doi:10.2337/diacare.29.04.06.dc05-2568

21. Lee KW, Ching SM, Ramachandran V, et al. Prevalence and risk factors of gestational diabetes mellitus in Asia: a systematic review and meta-analysis. BMC Pregnancy Childbirth. 2018;18(1):494. doi:10.1186/s12884-018-2131-4

22. Mak JKL, Lee AH, Pham NM, et al. Gestational diabetes incidence and delivery outcomes in Western China: a prospective cohort study. Birth. 2019;46(1):166-172. doi:10.1111/birt.12397

23. Gao C, Sun X, Lu L, Liu F, Yuan J. Prevalence of gestational diabetes mellitus in mainland China: a systematic review and meta-analysis. $J$ Diabetes Investig. 2019;10(1):154-162. doi:10.1111/jdi.12854

24. Yan B, Yu Y, Lin M, et al. High, but stable, trend in the prevalence of gestational diabetes mellitus: a population-based study in Xiamen, China. J Diabetes Investig. 2019;10(5):1358-1364. doi:10.1111/jdi.13039

25. Zhou B-F. Cooperative meta-analysis group of the working group on obesity in China. Predictive values of body mass index and waist circumference for risk factors of certain related diseases in Chinese adults-study on optimal cut-off points of body mass index and waist circumference in Chinese adults. Biomed Environ Sci. 2002;15(1):83-96.

26. Shao B, Mo M, Xin X, et al. The interaction between prepregnancy $\mathrm{BMI}$ and gestational vitamin D deficiency on the risk of gestational diabetes mellitus subtypes with elevated fasting blood glucose. Clin Nutr. 2019. doi:10.1016/j.clnu.2019.10.015

27. Jia X, Li N, Gao S, et al. The impact of self-reported preconception body mass index on gestational abnormal glucose tolerance in a Chinese center. J Diabetes Complicat. 2018;32(10):951-954. doi:10.1016/j.jdiacomp.2018.07.009

28. Zheng T, Ye W, Wang X, et al. A simple model to predict risk of gestational diabetes mellitus from 8 to 20 weeks of gestation in Chinese women. BMC Pregnancy Childbirth. 2019;19(1):252. doi:10.1186/s12884-019-2374-8
29. Kawanabe S, Nagai Y, Nakamura Y, Nishine A, Nakagawa T, Tanaka Y. Association of the muscle/fat mass ratio with insulin resistance in gestational diabetes mellitus. Endocr J. 2019;66 (1):75-80. doi:10.1507/endocrj.EJ18-0252

30. Wang Y, Luo B-R. The association of body composition with the risk of gestational diabetes mellitus in Chinese pregnant women: a case-control study. Medicine. 2019;98(42):e17576. doi:10.1097/ MD.0000000000017576

31. Boyle VT, Thorstensen EB, Thompson JMD, et al. The relationship between maternal 25-hydroxyvitamin D status in pregnancy and childhood adiposity and allergy: an observational study. Int J Obes. 2017;41(12):1755-1760. doi:10.1038/ijo.2017.182

32. Facca TA, Mastroianni-Kirsztajn G, Sabino ARP, et al. Pregnancy as an early stress test for cardiovascular and kidney disease diagnosis. Pregnancy Hypertens. 2018;12:169-173. doi:10.1016/j. preghy.2017.11.008

33. Piuri G, Ferrazzi E, Bulfoni C, Mastricci L, Di Martino D, Speciani AF. Longitudinal changes and correlations of bioimpedance and anthropometric measurements in pregnancy: simple possible bed-side tools to assess pregnancy evolution. J Matern Fetal Neonatal Med. 2017;30(23):2824-2830. doi:10.1080/ 14767058.2016.1265929

34. Kugananthan S, Gridneva Z, Lai CT, et al. Associations between maternal body composition and appetite hormones and macronutrients in human milk. Nutrients. 2017;9:3. doi:10.3390/nu9030252

35. Gridneva Z, Kugananthan S, Rea A, et al. Human milk adiponectin and leptin and infant body composition over the first 12 months of lactation. Nutrients. 2018;10(8):1125. doi:10.3390/nu10081125

36. Wang N, Ding Y, Wu J. Effects of pre-pregnancy body mass index and gestational weight gain on neonatal birth weight in women with gestational diabetes mellitus. Early Hum Dev. 2018;124:17-21. doi:10.1016/j.earlhumdev.2018.07.008

37. Hua X-G, Jiang W, Hu R, et al. Large for gestational age and macrosomia in pregnancies without gestational diabetes mellitus. J Matern Fetal Neonatal Med. 2019; 1-10. doi:10.1080/ 14767058.2019.1578746

38. Zhao R, Xu L, Wu ML, Huang SH, Cao XJ. Maternal pre-pregnancy body mass index, gestational weight gain influence birth weight. Women Birth. 2018;31(1):e20-e25. doi:10.1016/j.wombi.2017.06.003

39. Liu Y, Li G, Zhang W. Effect of fetal gender on pregnancy outcomes in Northern China. J Matern Fetal Neonatal Med. 2017;30 (7):858-863. doi:10.1080/14767058.2016.1189527

40. Schaefer-Graf UM, Graf K, Kulbacka I, et al. Maternal lipids as strong determinants of fetal environment and growth in pregnancies with gestational diabetes mellitus. Diabetes Care. 2008;31 (9):1858-1863. doi:10.2337/dc08-0039

\section{Publish your work in this journal}

Diabetes, Metabolic Syndrome and Obesity: Targets and Therapy is an international, peer-reviewed open-access journal committed to the rapid publication of the latest laboratory and clinical findings in the fields of diabetes, metabolic syndrome and obesity research. Original research, review, case reports, hypothesis formation, expert opinion and commentaries are all considered for publication. The manuscript management system is completely online and includes a very quick and fair peer-review system, which is all easy to use. Visit http://www.dovepress.com/testimonials.php to read real quotes from published authors. 